\title{
Digitalization of design and construction of agricultural facilities as a basis for ensuring their energy efficiency
}

\author{
Svetlana Uvarova ${ }^{1, *}$, Khuta Gumba $^{2}$, Elena Kiseleva $^{1}$, and Yaroslav Sonin ${ }^{1}$ \\ ${ }^{1}$ Voronezh State Technical University, October $20^{\text {th }}$ str. 84, 394006, Voronezh, Russia \\ ${ }^{2}$ Abkhaz State University, Universitetskaya str. 1, 384904, Sukhum, Republic of Abkhazia
}

\begin{abstract}
Energy saving and energy efficiency in modern conditions are an imperative of a stable evolutionary stage in the development of the country's investment and construction complex, while at the same time creating sustainable competitive advantages for both energy producers and its consumers when implementing a construction investment project. The use of digital technologies is postulated as one of the main resources of energy efficiency. The paper systematizes the resources and effects that are formed as a result of increasing the energy efficiency of construction projects in the agricultural sector. The paper substantiates the necessity and specifics of the information modeling technology application to increase the energy efficiency of objects, and also determines the results of the use of digital technologies, differentiating costs and effects.
\end{abstract}

\section{Introduction}

One of the main processes taking place in the global economic system is the transition to a digital economy in all sectors and fields of activity, including construction. Today in the development of the investment and construction complex of Russia there is an evolutionary stage, which can be concluded, focusing on the results of constructing a phase portrait of the investment and construction complex dynamics according to the criteria of the effectiveness of its activities and resource supply, indicating the presence of a transition to a stable attractor after 2009 (item 21 in Fig. 1).

However, the onset of the evolutionary stage of development does not mean the cessation of changes, based on the thesis proved in theoretical and methodological approaches of thesis in the undulating nature of organizational and economic processes [1]. The management system of the investment and construction complex, based on synchronization with the economic management system of the country and the world, is characterized by the fractality of the processes. Consequently, under the influence of external fluctuations caused by changes taking place in the global economy, it changes its state, taking into account the heredity of the system, its previous attractors and formed feedbacks [2].

*Corresponding author: uvarova_s.s@mail.ru 


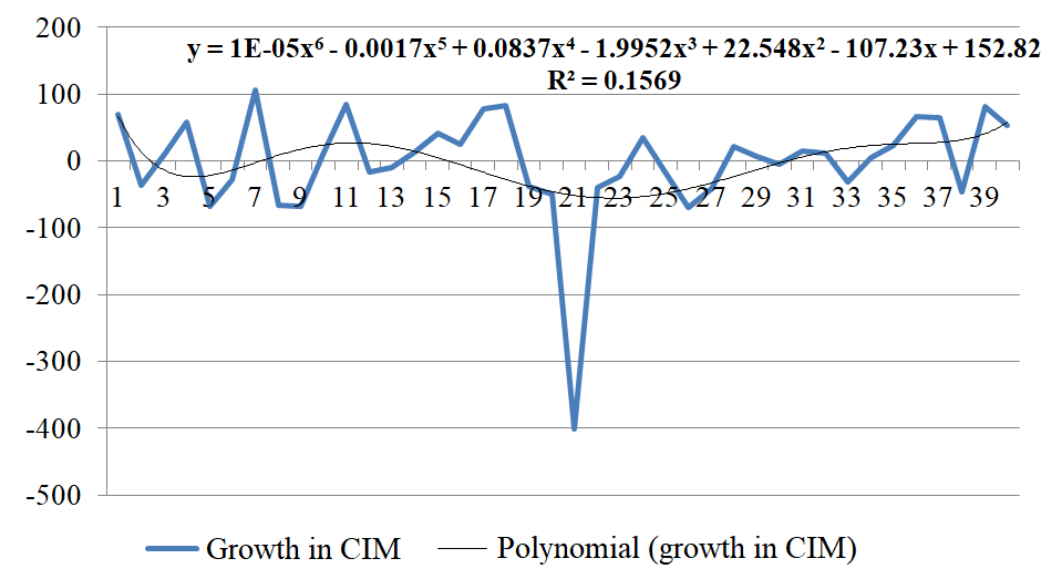

Fig. 1. Formalization of the dynamics of growth in the volume of construction and installation works, $\%$.

Based on the principle of fractality, the management system of the investment and construction complex in Russia reproduces the corresponding changes under the influence of external fluctuations, both on the basis of self-organization of the digitalization process of construction and on the basis of initiated changes at the macro level of management.

The aim of digitalization of construction is to create a digital environment for managing the life cycle of capital construction objects [3] not only to increase the implementing efficiency of the investment and construction projects at each stage of its life cycle, but also to create a single information system in the institutional plane, as well as for monitoring and audit of projects, optimization of the management of property at the operational stage, for the dissemination of best practices and the growth of innovation in investment and construction oh activity.

Information modeling technologies in construction provide the possibility of constant monitoring of stakeholders both over the implementation of investment and construction projects, and over the operation and overhaul of existing facilities and urban management based on increased energy efficiency.

Despite the downward trend in the level of energy intensity of products in the Russian Federation over the past few years, in absolute terms, this value is still high (Fig. 2).

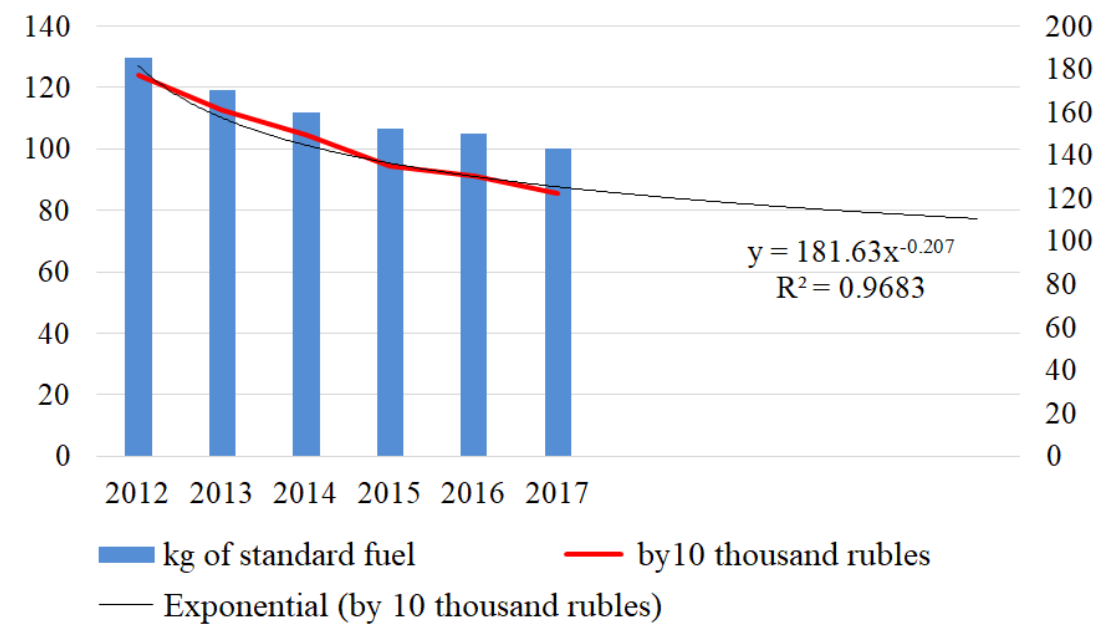

Fig. 2. Analysis and forecast of the energy intensity dynamics of products in the Russian Federation. 
The final result of the energy efficiency potential implementing in our country will be an increase in competitiveness both at the level of construction projects and, through enterprises and types of economic activity, at the level of regions and the economy of the country as a whole. It should be noted that competitiveness in this case represents the implementing of sustainable competitive advantages [4].

Energy efficiency as a competitive advantage is formed at three stages: resource (due to available energy resources, instrument metering and a certain level of energy consumption), investment (due to the development of energy audit, alternative energy) and innovative (through the implementation of product, process and organizational innovations, including digital energy modeling, innovations to minimize energy intensity, life cycle contracts and energy service contacts, and so on).

\section{Experimental}

Implementing of sustainable competitive advantages of energy efficiency provides a number of effects.

Regarding the types of effect obtained from improving energy efficiency, we should talk about the multiple nature of the effect, beginning with scientific, technical, environmental, social and ending with the economic effect of both an increase in the systemic competitiveness of the project and the enterprise, and from cost reduction during the project life cycle and building.

The reputation effect arising due to the increase in the business reputation of the enterprise is especially emphasized, since stable competitive advantages characterize the strategy of intellectual leadership within the framework of the systemic competitiveness concept. When assessing the effectiveness of investment in construction, aspects of the facility's environmental friendliness and its energy efficiency are considered by one way or another [4]. Most methods of investment analysis evaluate environmental risks, reputational risks and issues of regulation of the subject activity. The reputation of the developer or development company is also taken into account and depends on the sustainability factors disclosed in the financial statements. There is a fairly wide range of such standards, among them are global reporting initiative standards (GRI), the basics of integrated reporting (IR) an environmental, social and governance rating (ESG) and a number of other standards.

Reputation effects taken into account by non-financial parameters for evaluating investment projects are important for the investor, as they allow us to assess the impact on the region and the industry, clearly analyze the project risks and the quality of the risk management system, and also take into account the opportunities and limitations in implementing projects related to various aspects of sustainable development.

In general, the process of creating energy efficiency effects is presented in Figure 3. 


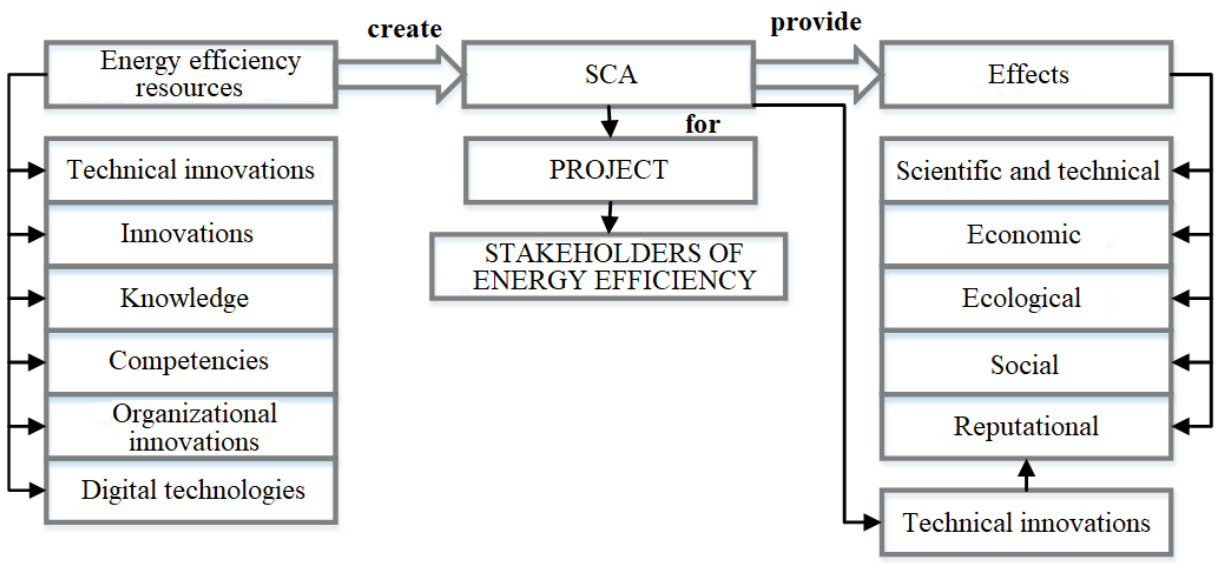

Fig. 3. The process of creating energy efficiency effects.

As the main resource of energy efficiency, it is necessary to determine innovations of all types: both product and process (technical and technological) and organizational. Innovative solutions for low-energy buildings are constantly being improved. At the same time, organizational mechanisms for improving energy efficiency on an innovative basis are being developed. Among organizational innovations, life cycle contracts should be highlighted, due to which the effectiveness of measures to reduce energy intensity and energy saving is achieved, since these effects, accompanied by the need for increased investment at the initial stage, achieve payback to a greater extent at the stage of operation of the construction project. Energy service contracts characterize similar efficiency (Fig. 4). The costs of energy-saving measures are borne by a service company that reimburses its costs by saving energy costs to the customer organization. The advantage of the energy service contract is that the organization does not need to attract its own or credit funds to modernize the equipment or implement other measures aimed at improving energy efficiency.

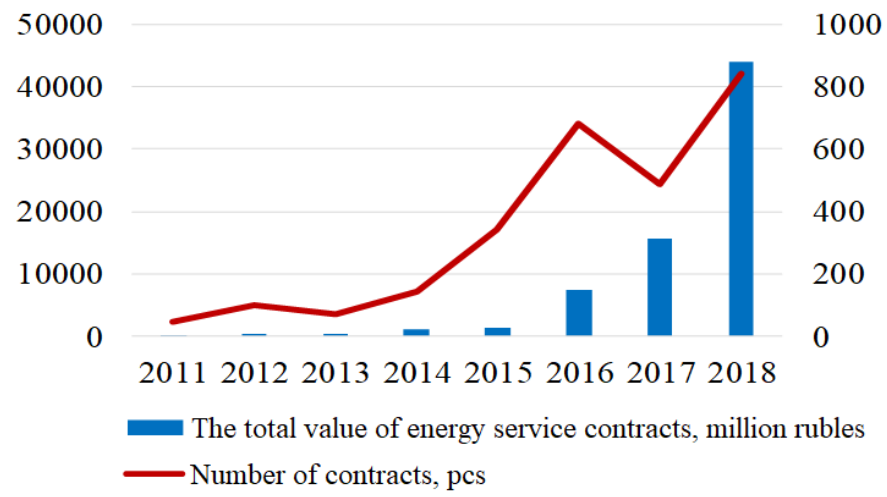

Fig. 4. Dynamics of energy service contracts in the Russian Federation.

A similar organizational innovation, involving the transfer of energy efficiency measures to outsourcing, is commissioning. Based on the study of foreign literature and regulatory and technical documents in the field of energy modeling and green certification, as well as the results of empirical studies, it can be concluded that building commissioning is an opportunity to reduce the energy consumption of buildings and the energy intensity of production and non-production activities, as well as reduce greenhouse gas emissions as 
part of reducing energy intensity and environmental impact. The implementation of the commissioning process creates a guarantee for the sustainability of the competitive advantage of energy efficiency, as it ensures the functioning of the building in accordance with the requirements of the customer or investor, not only by complying with the requirements for the design and construction of the facility, but also by creating the appropriate building maintenance service, ready to support the operation of the systems and equipment in design mode. Thus, the functions of commissioning include the functions of building audit, but have a wider scope, also performing the functions of organizing the process and participating in the development of documentation.

It is also possible to assess energy efficiency and develop recommendations based on the implementation of a range of energy audit procedures. However, despite the effectiveness of the organizational innovations listed above as a way of creating a sustainable competitive advantage in the framework of increasing the energy efficiency of a project, building or enterprise, one should take into account a number of institutional problems arising from their initiation and implementation of issued recommendations, as well as the initiated increase in costs at the construction stage to eliminate deficiencies identified by experts, which, if relevant information were available, would be easier and less costly to implement at the design and pre-design studies of the project.

On the basis of an automated control system (ACS) and automation systems for design solutions (CAD), it becomes possible not only to automate the process of preparing executive documentation, but also to create a digital model of an object in three dimensions (information modeling, or BIM technologies). Such technologies minimize the design errors and maximize the speed of decision-making on the choice of technology and equipment of an object, but BIM does not contain modules for solving the questions about energy efficiency of a building, since the information model does not contain information about energy processes occurring inside and outside the building.

Evaluation and modeling of the energy processes of the projected object is possible by applying the technology of modeling energy consumption and computational fluid dynamics (BEM and CFD). At the stage of construction and operation of the facility, the Internet of Things (IoT) technologies are used as key digital technologies, which allow realtime automated analysis and reporting on key indicators of energy efficiency, energy consumption and equipment maintenance management. Also, on the basis of real-time data received from IoT devices when they are processed by appropriate information analysis technologies, including artificial intelligence, recommendations are formed on improving approaches to energy management to ensure achievement of target energy efficiency indicators.

\section{Evaluation}

Information modeling should become as a technology designed to improve the performance indicators of modeling technologies and create a digital ecosystem for managing energy efficiency over the life cycle of capital construction projects. However, despite all the advantages of automation, not enough communications are formed between the information systems that are sufficient for downloading data. Also, automation does not provide the maximum reliability of information during design, which leads to the expenditure of a large amount of time on the search and verification of information.

As a rule, the BIM model contains an excess of information for CFD/BEM, since energy modeling takes into account only the surfaces of the object, which affect heat transfer, and in CFD, the components of the model, which affect the air flow, are taken into account. The main data for energy modeling are information on the dynamics of the weather, the parameters of the building systems, as well as models of the proposed 
equipment. The basic source data for CFDs are environmental and building parameters, air flow characteristics, and other data. Based on the above data, the corresponding calculations are performed, if necessary, the model is adjusted and new parameters are calculated. The use of BIM-modeling reduces the time and cost of preparing a calculation model of energy modeling by almost $90 \%$.

A schematic diagram of the formation of digitalization effects while ensuring energy efficiency is shown in Fig. 5.
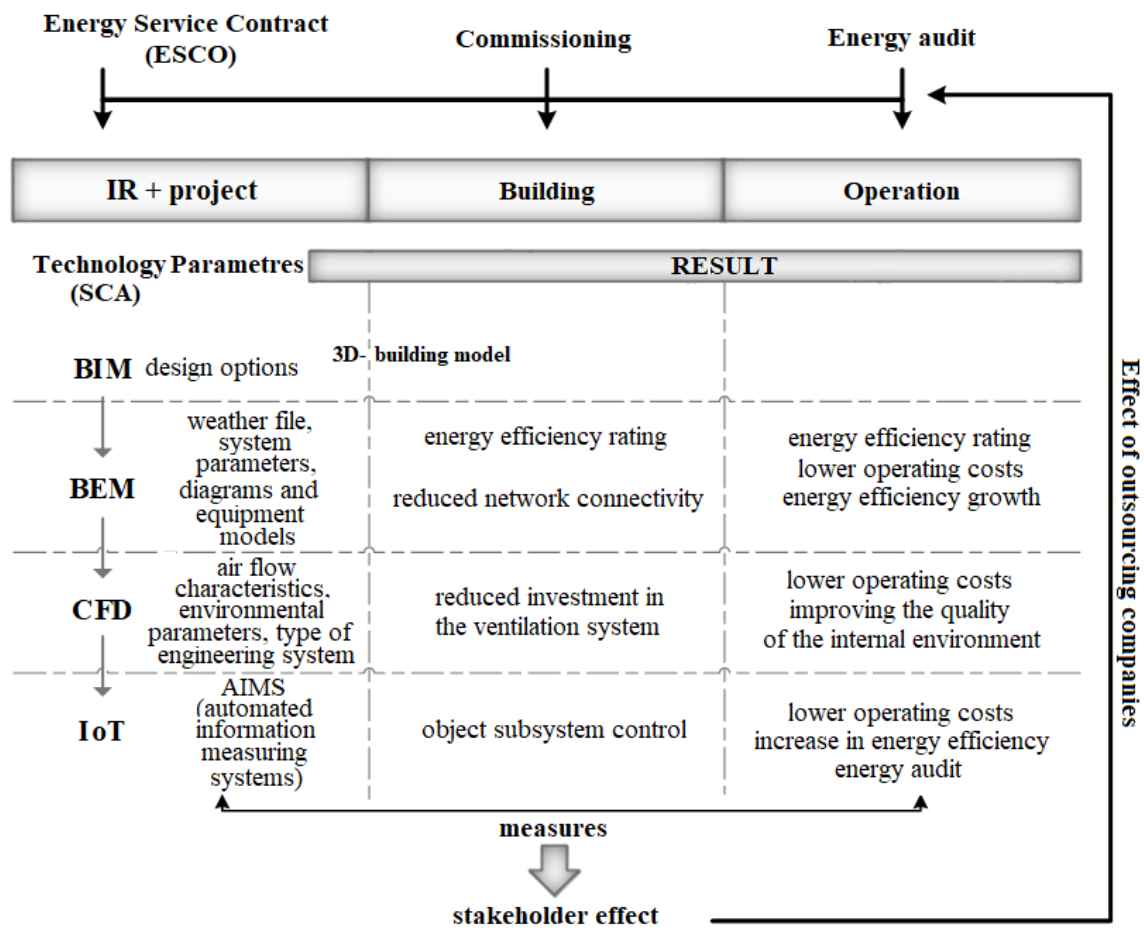

Fig. 5. Schematic diagram of the formation of energy efficiency results based on digitalization throughout the life cycle of an object.

Based on the high cost of creating BIM models, the frequent conflict of interdisciplinary interactions in the creation and functioning of the 3D model, the redundancy of information for energy modeling, the lack of qualified personnel, the digitalization of energy modeling at the project stage, as well as at the stage of implementation of recommendations at the subsequent stages of the investment project, it is possible to carry out based on CAD (Fig. $6)$.

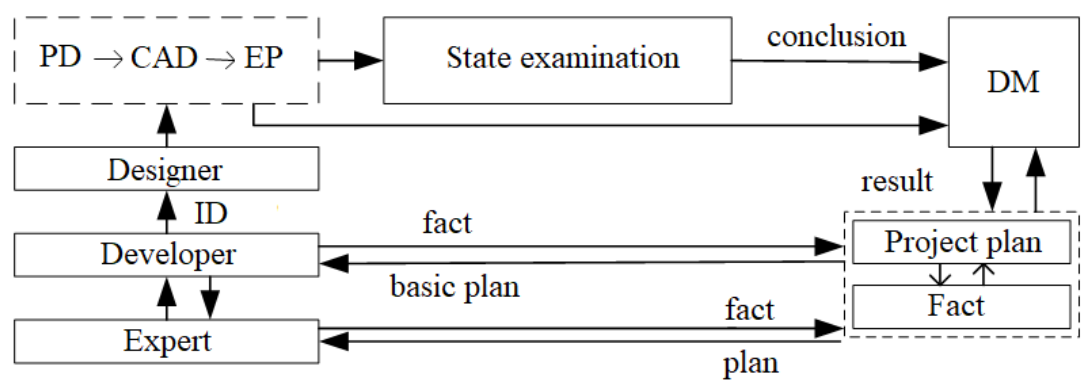

Fig. 6. Logical diagram of an automated management system of investment construction project. 
Automation includes not only performance of the calculations and drawings within the project stage, but, first of all, automation of interaction between the participants of the investment and construction project. So, in the automated control system presented above, the customer (developer) ensures the transfer to the designer of the initial data for the design. The project organization with the help of software develops project documentation, in which using specialized software determines the required amount of resources allocated to the estimated program, where the cost and labor costs of the project are calculated. Also, when setting the appropriate parameters, energy efficiency is evaluated based on processing in BEM and CFD systems. Based on the results of the state examination, using the project management software, a basic plan for the implementation of the project is developed, then adjusted or modified if necessary, with feedback from outsourcers. The practical application of such automated project management systems allows not only to reduce the complexity of project development by all participants in this process, including expert bodies, through the use of a single technical, mathematical and information support, but also to carry out input control of project documentation and manage the procurement of material resources and their supplies.

However, this scheme does not provide for the elimination of collisions, which, when designing new construction, are mostly spatial in nature, and when implementing measures to improve energy efficiency at the subsequent stages of the investment project, it is also temporary. According to expert estimate, the correction of one conflict at the construction stage costs from 50 to 300 thousand rubles.

In addition, it is necessary to ensure compliance of the proposed energy efficiency measures with the requirements of existing norms and standards, their inclusion in the estimate documentation, ensure the necessary approvals and organize workflow. Accordingly, there is a need to digitalize relevant business processes. At the same time, on the basis of the thesis about the need to eliminate conflicts, we consider it appropriate, especially with the already existing project documentation developed in $2 \mathrm{D}$, to translate it into an information model format with the interconnection of all business processes. The organizational scheme for digitalizing processes of developing measures for improving the energy efficiency during the development and implementation of a construction investment project is shown in Fig. 7. Possible digital CAD platforms are also presented there, and the effects and costs of the corresponding processes are determined.

We have differentiated the following types of effects and costs.

$E_{1}$ - the effect of compliance with standards, including reducing the time for approval, verification, etc.;

$E_{2}$ - the effect of increasing the accuracy of estimated calculations;

$\mathrm{E}_{3}$ - the effect of reducing the number of collisions, both spatial and temporal;

$\mathrm{E}_{4}$ - reduction of transaction costs associated with document management and performance discipline;

$E_{5}$ - the effect of reducing the number of changes required by the customer;

$\mathrm{E}_{6}$ - the effect of reducing the number of comments of the examination bodies;

$\mathrm{E}_{7}$ - improving the efficiency of energy efficiency measures;

$\mathrm{E}_{8}$ - reduction of costs for coordination and various procedures, as well as costs of energy modeling;

$\mathrm{E}_{9}$ - decrease in the number of comments on the results of construction control (corresponding reduction in the cost of correcting comments);

$\mathrm{E}_{10}$ - reduction of transaction costs for communications;

$\mathrm{Z}_{1}$ - increase in costs (when outsourcing to transfer to an information model, when information modeling on its own to purchase software products, training and the transition to a new design system);

$\mathrm{Z}_{2}$ - increase in costs for the integration of the BIM-model. 


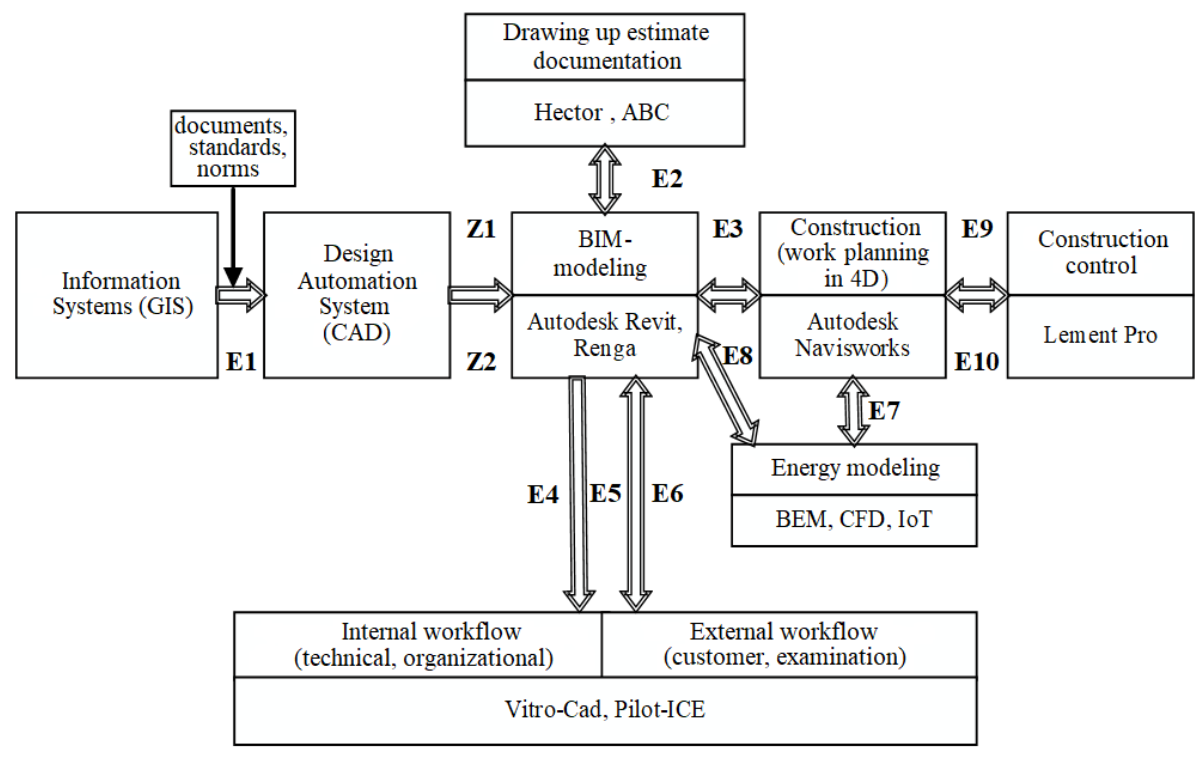

Fig. 7. Organizational scheme of digitalization of processes of developing measures for improving the energy efficiency in the development and implementation of a construction investment project.

Accordingly, the need to solve a large number of issues and process a large amount of information makes it necessary to increase the efficiency of communications management of the project, to increase the energy efficiency of the facility, which becomes possible with the reasonable use of information modeling taking into account the calculated efficiency.

\section{Conclusions}

1. In modern conditions of changing technological structure and transition to a digital economy, one of the most important energy efficiency resources allowing to create a sustainable competitive advantage is the use of digital technologies for the design, construction and operation of facilities in order to increase their energy efficiency.

2. A conclusion should be drawn on the need for improving the energy efficiency of analysis and processing of data on the current state of the energy intensity of a production, project or building, on the current level of energy consumption and ongoing energy-saving measures, on the use of alternative energy sources and the application of energy modeling in the project. Based on the collection and analysis of information on the existing energy efficiency potential through modeling, conclusions should be drawn on the directions and methods of improving energy efficiency.

3. Organizational innovations based on the use of digital technologies contribute to improving energy efficiency at all stages of the facility's life cycle by initially assessing the impact of future factors and choosing the optimal equipment, as well as by continuously monitoring subsystems and optimizing facility management and maintenance systems to further improve of energy efficiency and reduce operating costs.

4. The volumes, platforms and methods of information modeling, as well as the scale and sequence of digitalization of measures to increase the energy efficiency of facilities as creating sustainable competitive advantages should be determined by calculation when comparing costs and effects, including non-financial ones. 


\section{References}

1. S.S. Uvarova, A.A. Panenkov, Materials of the VI All-Russian Scientific and Practical Conference, 188-193 (2019)

2. S. Uvarova, L. Myshovskaya, K. Kulakov, MATEC Web of Conferences conference proceedings, 01119 (2018)

3. M. Tetik, A. Peltokorpi, O. Seppänen, J. Holmström, Automation in Construction 107, 102910 (2019)

4. H.M. Gumba, S.V. Belyaeva D.S. Voronov, S.E. Yerypalov, Economics and Entrepreneurship 3-1(80), 894-900 (2017) 